\title{
Management of migraine
}

\author{
Judith M Hockaday
}

\section{Definition and diagnosis}

Uncertainties about the definition of migraine and the absence of any 'test' or marker make its diagnosis difficult at any age. The difficulty is greater in children whose ability to recount previous or changing symptoms may be limited. Most importantly, children tend to present early in the course of headache disorders (because of parental anxiety) so that the reassurance of continued wellbeing in the face of a long history is unlikely.

Though diagnostic criteria are necessary for epidemiological study, they are unsatisfactory for clinical use, particularly in childhood, because for example, the visual phenomena of classical migraine are uncommon, and prostration, vomiting, and abdominal discomfort may overshadow the headache. ${ }^{12}$

In clinical practice it is simpler, and safer, to accept as migraine recurrent headaches which are paroxysmal (an essential characteristic), provided that there is return to full normal healthboth mental and physical-between attacks, that development continues normally, and that other causes of headache have been excluded (indications for investigation are given below). This demands a period of observation to establish that normal health is indeed maintained between attacks. Diagnosis is thus by exclusion, and longitudinal observation. ${ }^{1} \mathrm{~A}$ family history of migraine is not a reliable pointer to the diagnosis: the detail is often vague and the prevalence of migraine in the community is too high. The distinctions between common migraine (migraine without aura) and tension, and psychogenic, headaches may not be clear, and these disorders can coexist in children as well as adults. Their clinical management, however, overlaps.

There are probably no essential differences between migraine in childhood and that in adult life, though before puberty boys slightly outnumber girls. Basilar migraine is commoner in childhood, and other variants are probably also more often seen in childhood than in adults. It is also often stated that migraine equivalents are commoner in children.

\section{'EQUIVALENTS' OF MIGRAINE}

Although headache is an essential feature it is only one aspect of migraine and the neurological symptoms (including mental, motor, sensory, and autonomic disturbances) may be more prominent than the headache; rarely, they may occur without it - so called 'abortive migraine'. When abortive migraine consists of a scintillating scotoma in a subject who has classical

migraine attacks at other times the episode can properly be accepted as an 'equivalent' of migraine. When the disturbance consists of necessarily ill defined autonomic (so called vegetative or visceral) symptoms, in a child who has no other complaints the situation is different. The symptoms may represent abortive migraine but the list of alternative diagnoses is long and full investigation is essential. And unless or until recurrent paroxysmal headaches occur, the symptoms should not be labelled as migraine. Modification of symptoms by antimigraine remedies does not favour the diagnosis of migraine because a placebo effect is common. ${ }^{3}$

Careful observation and inquiry may reveal that headache is a feature in some presentations initially thought of as migraine equivalents, and this typically becomes clearer as time passes. Prospective studies in children with recurrent abdominal pain syndromes do not show migraine as a common sequel. ${ }^{4}$

\section{Indications for investigation}

Migraine should be seen in the context of unexplained headache - that is, headache without symptoms or signs indicating a specific diagnosis. Whenever possible it needs to be distinguished from tension headache and headache of psychogenic origin, and from true conversion (hysterical) headache. Most importantly, migraine needs to be distinguished from headache caused by intracranial disease that has not yet been detected, either because examination has been inadequate or presentation has been too early in the course of an evolving disorder. The nature of a headache does not indicate its aetiology, for example, headache caused by a brain tumour may be throbbing or unilateral, or show long remission ${ }^{5-7}$-and children with migraine may wake during the night or (occasionally) vomit without first feeling nauseated. ${ }^{8}$

The features that are indications for further

Indications for further investigation

- New neurological symptoms or physical signs

Failure to return to full normal health between attacks of headache

Increase in the frequency or severity of headaches

Headache not relieved by simple analgesics

Any suggestion of change in personality, behaviour, or performance of any skill at home or at school-for performance of any skill at home or at school-for
example, moodiness, irritability, lethargy, loss of interest, or fall in academic performance

University of Oxford, John Radcliffe Hospital, Oxford OX3 9D

Correspondence to: Dr Hockaday.
- Any suggestion of slowing of developmental progress, particularly in cognitive and motor skills

- Retarded physical growth

Head circumference exceeding the 97th centile, or considerably out of line with height

Young age (less than 6 years) 
investigation (by imaging and other tests) are shown in the table.

The duration of observation that is desirable before one can be confident that recurrent headaches are not the result of raised intracranial pressure is discussed by Honig and Charney, ${ }^{6}$ who noted that 60 of 72 children who presented with headaches caused by brain tumour were correctly diagnosed within four months of the onset of symptoms, and that of the remaining 12 children, 11 had symptoms or signs that should but did not lead to earlier diagnosis. These included small stature, polydipsia, alteration in character or frequency of headache, behavioural changes, visual features, and incoordination of movement. Flores et al noted worrying delays in the diagnosis of brain tumour in childhood, finding histories of longer than 26 weeks in 21 of 79 children. ${ }^{9}$

In general a child who develops unexplained headaches should be watched carefully for at least six months from its onset, and should be occasionally reviewed thereafter. It is clearly undesirable for children to visit a hospital clinic repeatedly and surveillance 'in passing' by the general practitioner and the community health service is more appropriate. Follow up should include attention to school progress (both social and academic) and to physical activities, and should include perusal of school reports.

\section{REASON FOR PRESENTATION}

The first step in treatment of migraine is to discover the reason for presentation: why has the child been brought at this particular point? The problem may be one of frequent worsening attacks, but equally may be of failure at school (primary or secondary), or parental anxiety (not always justified), and in these circumstances prescription of drugs may well increase the problem. Often parents just want reassurrance that they are managing the problem correctly; sometimes they come only to inquire about some widely advertised new drug, or they have heard of an aquaintance with a brain tumour. Medicinal treatment is indicated only if the reason for consultation lies in the child.

\section{PROVOKING FACTORS}

Many children with migraine also have tension headaches, and sometimes in addition psychogenic headaches masking school refusal. The prominence of these aspects will indicate whether psychiatric referral is indicated.

Provoking factors are often closely interrelated. They include stress, fasting, food factors, fatigue, light, and minor head trauma (including football). ${ }^{10}$ Most are inconsistent in their effects, so that while sometimes active they are at other times harmless. Parents may lack information about bullying in school or may withhold information about neglect and abuse. A single consultation is rarely enough in children: parents often need guidance about what to look for before an adequate history is obtained, and in most cases a school report is necessary. A lot of attention is given to dietary factors in migraine, ${ }^{11}$ but the prevalence of dietary mig- raine is uncertain and there are important reservations about the use of elimination or exclusion diets in childhood on grounds of health, ${ }^{12}$ compliance, and cost. ${ }^{13} \mathrm{~A}$ controlled study in children showed equal benefit from, and no differences between, a diet high in fibre and the same diet excluding vasoactive amines. ${ }^{14}$ Some 'alternative treatments' are aimed at reducing stress, which is a well recognised provoking factor in all benign recurrent headache disorders in children. There is no evidence that sophisticated manoeuvres such as acupuncture and biofeedback are superior to the 'ordinary' psychotherapy implicit in the process of diagnosis, explanation, and reassurance. ${ }^{15}$

\section{Treatment}

Wherever possible non-medicinal treatment should be used, aimed at altering the child's circumstances. Treatment may include removal of such distant causes as batswing ears (leading to bullying, failure at school, and frequent migraine) or tonsillectomy (relieving sleep apnoea, daytime fatigue, school failure, and increasing migraine with or without tension headache). There is no value in specific headache medication in children with psychogenic symptoms.

\section{TREATMENT OF THE ACUTE ATTACK}

Medication should be given at the first symptom of an impending attack. For children of school age it should be easily available in school so that the child may avoid being sent home, instead being encouraged to return to class after a brief rest.

Initial drug treatment should offer a means of pain relief: once this has been experienced much anxiety (and therefore risk of further attacks) is reduced. Analgesic treatment should be given early in sufficient dose in absorbable form. Soluble paracetamol or aspirin (the use of which is limited in the United Kingdom), sometimes with metoclopramide (of unproved benefit and with a high risk of dystonic reactions in children ${ }^{16}$ ) usually give relief especially if followed by a brief rest in a darkened room.

When migraine attacks are severe and simple remedies have failed then codeine may be tried, and parenteral diazepam or chlorpromazine can be used if the child is distressed. Use of these drugs must be cautious, and over medication is common. Ergotamine preparations can be used in children, with the usual cautions about dose and frequency of administration. There is reluctance to prescribe ergotamine for children under the age of 10 years, but its use is justified in severe presentations. When vomiting heralds an attack of migraine then sublingual, intramuscular, or rectal administration will be necessary. Propranolol is beneficial in treatment of acute attacks in adults, but has not been used in this way in children. ${ }^{17} \mathrm{~A}$ controlled study of the calcium channel blocker nifedipine in treatment of acute attacks in adults showed no beneficial effect. ${ }^{18}$

INTERVAL TREATMENT

Most children with migraine (and their parents) 
find that effective pain relief for each headache as it occurs is adequate treatment. For the few in whom relief cannot be found or who continue to experience frequent attacks, then interval drug treatments must be tried. There is no proved effective prophylactic against migraine in children. Despite early favourable reports recent controlled studies of propranolol, timolol maleate, clonidine, and pizotifen all failed to show any superiority over placebo. ${ }^{19} \mathrm{~A}$ controlled trial of dihydroergotamine as a prophylactic in children showed no benefit. ${ }^{20}$ There are promising reports of the effects of flunarizine, ${ }^{21}$ and other calcium channel blockers, and side effects observed in adults ${ }^{22}$ have not been seen in children. ${ }^{21} \mathrm{~A}$ controlled trial of $\mathrm{L}$ 5hydroxytryptophan in children with migraine gave negative results, ${ }^{23}$ but there is interest in the development of new 5-hydroxytryptophan agonist drugs, which have not yet been tried in children. With increasing understanding of the adverse effects of antiepileptic drugs on cognition there is no longer a place for their use in headache disorders, except in the rare cases of true seizure headaches. ${ }^{24}$ Disability from migraine is rare, but it can be considerable with severe effects on schooling and behaviour, and there remains great need for effective prophylaxis.

\section{Conclusion}

Most children with benign headaches, whether migraine or tension headaches, respond within a few months to reassurance, general advice, and simple remedies for attacks as they arise. Because most children do improve, or show natural remission, failure to respond should be regarded as an indication to reconsider the diagnosis.

Until migraine can be identified by some investigation or marker it should remain within the area of headache problems in general, with diagnosis by exclusion of other causes.

1 Hockaday JM. Definitions, clinical features and diagnosis of migraine. In: Hockaday JM, ed. Migraine in childhood. migraine. In: Hockaday JM, ed. Mign
London: Butterworths, 1988:5-24.
2 Linet MS, Stewart WF. Migraine headache: epidemiologic perspectives. Epidemiol Rev 1984;6:107-39.

3 Anonymous. Treatment of migraine. [Editorial]. Lancet 1982;i: $1338-40$.

4 Hockaday JM. Migraine and its equivalents in childhood. Dev Med Child Neurol 1987;29:258-70

5 Raskin NH, Apenzeller O. Headache. Major problems in internal medicine 19. Philadelphia: Saunders, 1980.

6 Honig PJ, Charney EB. Children with brain-tumour headaches. Am $\mathcal{F}$ Dis Child 1982;136:121-4.

7 Novak GP, Moshe SL. Brainstem glioma presenting as paroxysmal headache. Dev Med Child Neurol 1985;27: 379-82.

8 Congdon PJ, Forsythe WI. Migraine in childhood: a study of 300 children. Dev Med Child Neurol 1979;21:209-16.

9 Flores LE, Williams DL, Bell BA, et al. Delay in the diagnosis of pediatric brain tumours. Am J Dis Child 1986;140: 684-6.

10 Haas DC, Pineda GS, Lourie H. Juvenile head trauma syndromes and their relationship to migraine. Arch Neurol 1975;32:727-30.

11 Egger J, Carter CM, Wilson J, et al. Is migraine food allergy? A double-blind controlled trial of oligoantigenic diet treatment. Lancet 1983;ii:865-9.

12 Hughes M, Clark N, Forbes L, Colin-Jones DG. A case of scurvy. Br Med $\mathcal{F}$ 1986;293:366.

13 MacDonald A, Forsythe WI, Minford AMB. Practical problems associated with the dietary management of migraine. In: Rose FC, ed. Current problems in neurology: 4. Advances in headache research. (Proceedings of the Sixth International Migraine Symposium). London: John Libbey, 1987:113-6. alfield SAW, Wardley BL, Houlsby WT, et al. Controlled study of exclusion of dietary vasoactive amines in migraine. Arch Dis Child 1987;62:458-60.

15 Fentress DW, Masek BJ, Mehegan JE, Benson H. Biofeedback and relaxation response training in the treatment of paediatric migraine. Dev Med Child Neurol 1986;28: $139-46$

16 Gatrad AR. Dystonic reactions to metoclopramide. Dev Med Child Neurol 1976;18:767-9.

17 Tokola R, Hokkanen E. Propranolol for acute migraine. $\mathrm{Br}$ Med f 1978;ii: 1089 .

18 Kanter R, Hoffert MJ, Scholz M, Cleeland C, Kabler JD. A prospective study of nifedipine in aborting acute attacks of classical migraine. Proceedings of the Second International Headache Society Congress. Copenhagen: 1985:148-9.

19 Forsythe WI, Hockaday JM. Management of childhood mig raine. In: Hockaday JM, ed. Migraine in childhood. London: Butterworths, 1988:63-74.

20 Pothman R, Winter K. Migraine prophylaxis with dihydroergotamine - a double-blind placebo-controlled dihydroergotamine - a double-blind place
study. Cephalalgia 1989;9(suppl 10):428-9.

21 Sorge F, De Simone R, Marano E, Nolano M, Orefice G, Carrieri $P$. Flunarizine in the prophylaxis of childhood migraine. A double-blind placebo-controlled crossover study. Cephalalgia 1988;8:1-6.

22 Chouza C, Scaramelli A, Caamano JL, De Medina O, Aljanati R, Romero S. Parkinsonism, tardive dyskinesia, akathisia, and depression induced by flunarizine. Lancet 1986;i: $1303-4$.

23 Santucci M, Cortelli P, Rossi PG, Baruzzi A, Sacquegna T. L S-hydroxytryptophan versus placebo in childhood migraine prophylaxis: a double-blind crossover study. migraine prophylaxis: a

24 Hockaday JM, Newton RW. Migraine and epilepsy. In: Hockaday JM, ed. Migraine in childhood. London: Butterworths, 1988: 88-104. 